\title{
DO GATT À OMC: O QUE MUDOU, COMO \\ FUNCIONA E PERPECTIVAS PARA O SISTEMA \\ MULTILATERAL DE COMÉRCIO
}

Cláudio Ferreira da Silva ${ }^{1}$

\section{Breve Histórico, Rodada do Uruguai e relações Norte-Sul}

Iniciada em 1986 em Punta Del Este e finalizada em abril de 1994 em Marraqueche foi a mais ampla e complexa negociação sobre comércio internacional, envolveu cerca de 100 países.

A estrutura negociadora compreendia um Comitê de Negociações Comerciais, presidido pelo Diretor-Geral do GATT, Arthur Dunkel e 15 grupos negociadores, para cumprir seus respectivos mandatos dentro do prazo de quatro anos. Sendo a primeira na qual a iniciativa de convocação da Rodada não coube aos Estados Unidos, mas sim ao Japão. Nunca na história do GATT houve resistência tão grande aos interesses dos Estados Unidos, graças ao declínio relativo de sua economia nos anos 80 e da enorme pressão imposta pela União Européia e pelo Japão. Os Estados Unidos foram denunciados, pela primeira vez, como o maior violador das normas do GATT e o principal responsável por práticas comerciais não eqüitativas.

Os Estados Unidos, que emergiram ao final da $1^{\text {a }}$ Grande Guerra como uma nova potência mundial, recusaram-se a participar dos esforços para a retomada do processo de liberalização do comércio internacional e de integração da economia mundial, em curso desde a segunda metade do século XIX.

A partir da segunda metade do século XIX, as maiores nações européias passaram a firmar entre si e com os Estados Unidos vários acordos comerciais bilaterais. Nesse processo, a França ocupou um

\footnotetext{
${ }^{1}$ Professor de Comércio Exterior do Curso de Relações Internacionais do Centro Universitário UniCEUB.
}

Universitas - Relações Int., Brasília, v. 2, n.2, p. 109-125, jul./dez. 2004 
papel destacado ao difundir a utilização da cláusula de nação mais favorecida, que estendia a todos os países os benefícios negociados bilateralmente.

Após a quebra da Bolsa de Nova York em 1929, assumiram um comportamento acentuadamente protecionista, aumentando suas tarifas aduaneiras de $38 \%$ para $52 \%$ (Smoot-Hawley Act), fato que levou seus parceiros a impor restrições comerciais e a desvalorizar suas moedas.

Tal comportamento se disseminou, culminado na imposição de barreiras comerciais cada vez maiores.

Assim, o protecionismo norte-americano terminou levando a um resultado exatamente oposto ao esperado, pois reduziu o seu comercio externo, ajudando a aprofundar a depressão que se queria atenuar.[Krugman e Obstfeld, 1994, p.241].

Ao final da $2^{\mathrm{a}}$. Guerra Mundial, a postura dos Estados Unidos era bastante distinta daquela adotada após a $1^{\mathrm{a}}$. Guerra Mundial. Temendo a repetição da guerra comercial dos anos 30 (que contribuíram para deflagrar) e conscientes de que negociações bilaterais por si só não seriam suficientes para garantir a cooperação em nível mundial nem os mercados para seus produtos manufaturados, assumiram então a liderança da liberalização multilateral do comércio. Foi sob seus auspícios que o Conselho Econômico e Social da recémcriada Organização das Nações Unidas (ONU) convocou uma Conferência sobre o Comércio e Emprego. Nela foi apresentado o documento intitulado Acordo Geral sobre Tarifas e Comércio (GATT), que foi escrito basicamente pelos Estados Unidos e a Inglaterra, propunha regras multilaterais de comércio internacional, com o objetivo de evitar a repetição da onda protecionista que marcou os anos 30 .

Posteriormente, outras sugestões foram incorporadas, e o Acordo foi assinado por 23 países, entre eles o Brasil, durante a Rodada Genebra (1947), a primeira das grandes rodadas de negociações multilaterais de comércio.

O principal objetivo do GATT era a diminuição das barreiras comerciais e a garantia de acesso o mais eqüitativo aos mercados por parte de seus signatários e não a promoção do livre comércio. Seus idealizadores acreditavam que a cooperação comercial aumentaria a

Universitas - Relações Int., Brasília, v. 2, n.2, p. 109-125, jul./dez. 2004 
interdependência entre os países e ajudaria a reduzir os riscos de uma nova guerra mundial [Hoekman e Kostecki, 1995, p. 15].

O Acordo deveria ter um caráter provisório e vigir apenas até a criação da Organização Internacional de Comércio (OIC).

As negociações para tanto foram realizadas na Conferência de Havana em 1948, mas a OIC terminou não sendo criada em razão da recusa do Congresso norte-americano em ratificar o Acordo. Assim, o sistema idealizado em Bretton Woods ficou apenas com dois pilares o Fundo Monetário Internacional (FMI) e o Banco Mundial.

O GATT incorporou muitas das provisões da OIT, contidas na Carta de Havana (subscrita por 53 países, inclusive o Brasil), e foi adquiridas progressivamente atribuições de uma organização internacional. No entanto,não perdeu o seu caráter de acordo provisório nem obteve uma personalidade jurídica própria, como o FMI e o Banco Mundial.

Além da onda protecionista, outros movimentos reforçaram a percepção de que as regras multilaterais de comércio vigentes eram insuficientes para dar conta da nova realidade do comércio internacional: por um lado, a economia se globalizava, os fluxos de capitais cresciam e o comércio de serviços tornava-se crescentemente mais importante para muitos países; e por outro, as regras multilaterais continuavam na prática, e mesmo assim com exceções, restritas ao comércio de bens manufaturados. Não havia um acordo entre sobre salvaguardas, regras para imposição de direitos para compensar a existência de dumping ou subsídios eram bastante precárias, sendo utilizadas de forma discricionária e protecionista.

Tudo isso, aliado ao tremor de que se repetissem as guerras comerciais dos anos 30 , levou à realização da mais ampla e ambiciosa rodada de negociações de todo o pós-guerra - a Rodada Uruguai.

Estava caracterizado pelo impasse de dois grupos de interesse composto por países desenvolvidos que defendiam a introdução de novos temas como serviços e propriedade intelectual (Segundo Rubens Ricupero relacionados indiretamente ao comércio), e países em vias de desenvolvimento (reunidos no chamado Grupo dos 77 -G77, com destaque para Brasil, Índia, Argentina e Iugoslávia, Paquistão e Egito) que defendiam negociações em áreas tradicionais como agricultura e

Universitas - Relações Int., Brasília, v. 2, n.2, p. 109-125, jul./dez. 2004 
têxtil (ainda segundo Ricupero "medidas de fronteira" tradicionais sob a forma de tarifas altas, picos tarifários, escalada tarifária e de medidas não-tarifárias).

O Brasil e outras economias relativamente fechadas viam com reservas a disposição dos EUA e, em menor medida, da Comunidade Econômica Européia, de estender as regras do GATT ao comércio de serviços e de estabelecer regras substantivas para a proteção de direitos de propriedade intelectual, porque não contavam em seu ordenamento jurídico com leis e regulamentos sobre essas matérias e, do seu ponto de vista, poucas vantagens comerciais poderiam ser auferidas dessas propostas.

Para Ricupero conceder prioridade aos temas não-comerciais teria quatro conseqüências desastrosas:

a) sobrecarga no sistema;

b) a ordem natural de prioridades seria invertida;

c) os países que necessitam de maior liberalização precisariam recorrer a acordos bilaterais e regionais para ver os seus interesses atendidos;

d) aumento da hostilidade pública ao sistema, proveniente quase exclusivamente da reação aos temas comerciais nãotradicionais.

Neste paradoxo entre interesses dos países do Norte versus países do Sul transcorridos sete anos do fim da Rodada do Uruguai pode-se constatar a inclusão de medidas que protegem alguns dos mais importantes interesses comercias dos países avançados e o impacto que estas medidas possuem na participação dos países em desenvolvimento- a questão das "medidas de fronteira" tradicionais continua viva na agenda comercial, impedem o sistema de realizar toda sua potencialidade.

Vale destacar, a propósito as diferentes esferas "geocomerciais" em que o Brasil projeta-se entre fins de 1994 e princípios de 1995 : no âmbito sub-regional, o Mercosul (TEC e personalidade jurídica), no âmbito hemisférico na Cúpula de Miami a idéia de se conformar, até o ano 2005, uma área de livre comércio para as Américas(Alca)

Universitas - Relações Int., Brasília, v. 2, n.2, p. 109-125, jul./dez. 2004 
envolvendo todas as economias do continente, á exceção de Cuba.e no âmbito multilateral, entra em funcionamento a OMC.

Em dezembro de 1990, prazo estabelecido para o encerramento da Rodada, um impasse foi atingido em Bruxelas, principalmente na área da agricultura, e a Rodada fica bloqueada.

$\mathrm{O}$ acordo de Marraqueche, que engloba todas as áreas negociadas durante a Rodada, foi assinado em abril de 1994. A OMC finalmente entra em operação em janeiro de 1995. Os principais temas negociados foram:

a) Criação da OMC;

b) rebaixamento tarifário para produtos industriais e para produtos agrícolas;

c) reincorporação dos produtos agropecuários ao sistema multilateral de comércio;

d) reforço das regras do GATT: anti-dumping, subsídios, salvaguardas, regras de origem, etc;

e) negociação de um novo processo de soluções de controvérsias, que dotou a nova OMC de maior credibilidade;

f) prazos de implantação dos temas negociados mais alargados, em especial, para países em desenvolvimentos;

g) negociação de diversos artigos do Acordo Geral do GATT, nos seguintes temas: formação de acordos preferenciais de comércio, balanço de pagamentos, alterações de listas e negociações de tarifas e empresas estatais de comércio exterior.

A Rodada Uruguai apresentou avanços em áreas tradicionais, bem como firmaram-se acordos setoriais para a agricultura e o setor têxtil. Destacando-se, fundamentalmente, a criação da OMC, a qual ficou encarregada de conduzir todos os acordos concluídos sob os auspícios daquela rodada.

Assim, os documentos resultantes são: a Ata Final da Rodada Uruguai, o Acordo constitutivo da OMC e quatro anexos. O Anexo 1 é formado pelos Acordos Multilaterais de Comércio de Bens (Gatt 94),

Universitas - Relações Int., Brasília, v. 2, n.2, p. 109-125, jul./dez. 2004 
Acordo Geral sobre o Comércio de Serviços (Gats), Acordo sobre Aspectos dos Direitos de Propriedade Intelectual relacionados ao Comércio (Trips).

O Anexo 2 trata das resoluções de disputas no âmbito da OMC. O mecanismo de Exame de Políticas de Comércio e Alguns Acordos de Comércio Plurilaterais (Compras governamentais, Aeronaves Civis, Tecnologia da Informação) encontram-se nos Anexos 3 e 4, respectivamente. Veja a estrutura do Acordo, a seguir:

\section{Estrutura do Acordo da OMC}

ACORDO DE MARRAQUECHE (15/04/94)

Acordo Constitutivo da Organização Mundial do Comércio

\section{ANEXO I}

\section{ANEXO I A}

1. Acordo Geral sobre Tarifas e Comércio 1994 (Gatt)

Entendimento sobre a Interpretação do Artigo II.1.b do Gatt 1994

Entendimento sobre a Interpretação do Artigo XVII do Gatt 1994

Entendimento sobre Disposições Relativas a Balanço de

Pagamentos do Gatt 1994

Entendimento sobre a Interpretação do Artigo XXIV do Gatt 1994

Entendimento sobre Derrogações (waivers) de Obrigações sob o Gatt 1994

Entendimento sobre a Interpretação do Artigo XXVIII do Gatt 1994

Protocolo de Marraqueche ao Gatt 1994

2. Acordo sobre Agricultura

3. Acordo sobre Aplicação de Medidas Sanitárias e Fitossanitárias

4. Acordo sobre Têxteis e Vestuário

5. Acordo sobre Barreiras Técnicas ao Comércio

6. Acordo sobre Medidas de Investimento Relacionadas ao Comércio

Universitas - Relações Int., Brasília, v. 2, n.2, p. 109-125, jul./dez. 2004 
7. Acordo sobre a Implementação do Artigo VI do Gatt 1994

8. Acordo sobre a Implementação do Artigo VII do Gatt 1994

9. Acordo sobre Inspeção Pré-Embarque

10. Acordo sobre Regras de Origem

11. Acordo sobre Procedimentos para o Licenciamento de Importações

12. Acordo sobre Subsídios e Medidas Compensatórias

13. Acordo sobre Salvaguardas

ANEXO I B

Acordo Geral sobre Comércio de Serviços (Gats)

ANEXO I C

Acordo sobre Aspectos dos Direitos de Propriedade Intelectual

Relacionados ao Comércio (Trips)

ANEXO II

Entendimento Relativo às Normas e Procedimentos sobre Soluções de Controvérsias

ANEXO III

Mecanismo de Revisão de Políticas Comerciais

ANEXO IV

Acordos Plurilaterais de Comércio

1. Acordo sobre Comércio de Aeronaves Civis

2. Acordo sobre Compras Governamentais

3. Acordo Internacional sobre Produtos Lácteos

4. Acordo Internacional sobre Carne Bovina

\section{A Organização Mundial de Comércio (OMC): Objetivos e Estrutura}

A organização se constitui como um foro para a continuação do processo de negociações na área do comércio, visando sempre uma maior liberalização do comércio de bens e serviços, além de espaço para temas relacionados, tais como: meio ambiente, investimentos, concorrência, facilitação de comércio, comércio eletrônico e clausulas sociais.

A estrutura legal da OMC engloba as regras estabelecidas pelo antigo GATT, depois da Rodada do Uruguai, surge o termo "GATT

Universitas - Relações Int., Brasília, v. 2, n.2, p. 109-125, jul./dez. 2004 
1994" as modificações e resultados das negociações passadas de liberalização de comércio, além de todos os resultados da Rodada Uruguai.

Os objetivos vão mais além da liberalização comercial sobretudo a busca do crescimento e desenvolvimento econômico internacionais. Em síntese, o Acordo reconhece a importância do conceito de desenvolvimento sustentável dentro da área do comércio internacional, além de reconhecer a necessidade de assegurar aos países em desenvolvimento uma maior parcela no comércio.

A não-discriminação é o princípio fundamental do sistema multilateral de comércio e está expresso nos acordos do GATT/OMC através de duas regras: as cláusulas de nação mais favorecidas e do tratamento nacional.

\section{Funções da OMC:}

a) implantar acordos da Rodada Uruguai;

b) constituir um foro para as negociações comerciais entre os Estados-membros;

c) administrar o Entendimento- Regras e Procedimentos Relativos às Soluções de Controvérsias;

d) administrar o Mecanismo de Revisão de Políticas Comerciais.

\section{Estrutura da OMC:}

a) Conferência Ministerial - órgão máximo da organização, composta pelos representantes dos Estados-membros, a cada dois anos;

b) Conselho Geral - composto por embaixadores das missões permanentes junto à organização que deverá se reunir quando apropriado;

c) Secretariado - chefiado por um Diretor Geral designado pela Conferência Ministerial, e vários vice-diretores assessorados por um corpo técnico, com responsabilidades institucionais;

Universitas - Relações Int., Brasília, v. 2, n.2, p. 109-125, jul./dez. 2004 
d) diversos órgãos - solução de controvérsias, revisão de política comercial;

e) conselhos para bens, serviços e propriedade intelectual;

f) diversos comitês - subordinados aos conselhos, cerca de 30 .

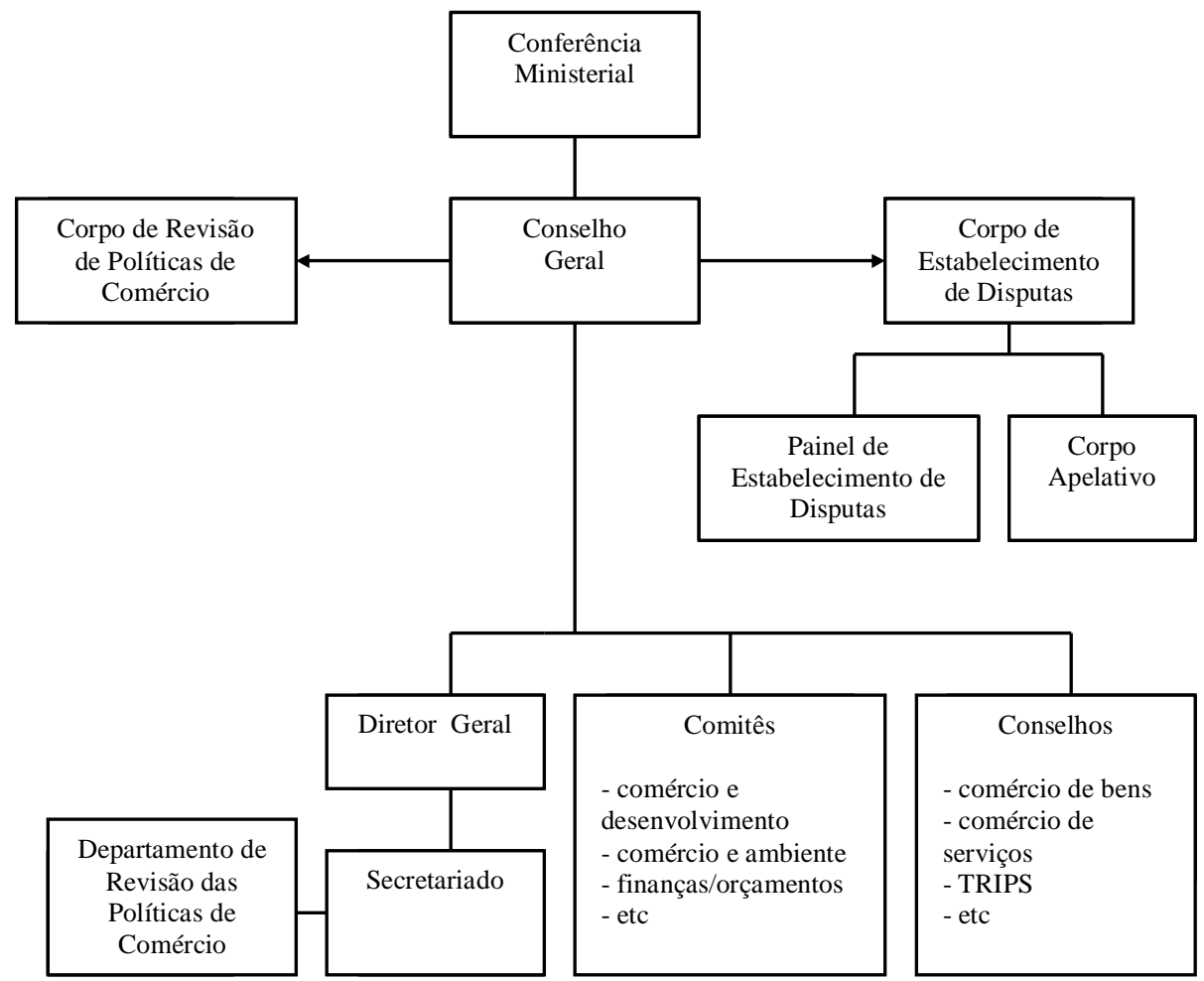

\section{$\underline{\text { O Processo de Tomada de Decisões }}$}

A OMC toma decisões por consenso, isto é, quando nenhum país membro se opõe formalmente a uma decisão. Se o consenso não é possível, a decisão é tomada por maioria, em votação na qual cada país terá um voto.

O acordo adota maiorias qualificadas para a tomada de decisões nos seguintes casos:

Universitas - Relações Int., Brasília, v. 2, n.2, p. 109-125, jul./dez. 2004 
- A interpretação das disposições de qualquer dos acordos requer maioria de três quartos (Acordo sobre a OMC, Artigo IX, 2).

- As emendas, em geral, requerem maioria de dois terços. Isso, não obstante, as modificações do Acordo sobre a OMC, Artigo $\mathrm{X}, 1,2$.

- As disposições do GATT de 1994, do GATS e do Acordo de TRIPS relativas ao tratamento NMF (Tratamento da nação mais favorecida) apenas surtirão efeito quando aceitas por todos os membros.

- As solicitações de isenção temporária apresentada por país membro a respeito das obrigações impostas pela OMC requerem, para sua aceitação, de maioria de três quartos (Acordo sobre a OMC, Artigo IX, 2).

Sobre os mecanismos de solução de controvérsias a Organização somente entra em ação mediante a solicitação de um ou mais Estados-membros, após fracasso de entendimentos bilaterais (Consultas Bilaterais). O Conselho Geral administra o sistema de disputas comerciais, funcionado como um Órgão de Solução de Controvérsias, que tem a autoridade para estabelecer "painéis";

\section{Análise comparativa entre o Sistema GATT e o novo Sistema OMC}

Sobre as modificações em relação ao sistema anterior, cabe destacar algumas diferenças entre o GATT e a OMC:

GATT: era um acordo multilateral, de caráter provisório e sem base institucional, com uma pequena secretaria associada, que surgiu em 1947, nunca teve o poder suficiente para impedir que seus signatários se desviassem por caminhos protecionistas.

Os signatários dos acordos do Gatt eram chamados de partes contratantes. As normas do Gatt restringiam-se ao intercâmbio de mercadorias. O Gatt possuía muitos acordos de caráter plurilateral

Universitas - Relações Int., Brasília, v. 2, n.2, p. 109-125, jul./dez. 2004 
(os chamados códigos), dado que muitas das regras não forma subscritas por todos os países.

OMC: é uma organização permanente, com personalidade jurídica própria, os compromissos sob seus auspícios são absolutos e permanentes, e o seu sistema de solução de controvérsias é mais efetivo e menos sujeito a bloqueios. Os signatários dos acordos do Gatt eram chamados de membros. As normas da OMC cobrem comércio de bens, serviços, propriedade intelectual. Já na OMC os acordos são praticamente todos multilaterais, ou seja, subscritos integralmente pelos membros.[Rêgo, 1996, p.12]

\section{Os princípios básicos das Regras do Sistema OMC}

Os chamados acordos da OMC, que englobam o GATT de 1947 e os resultados da Rodada Uruguai, contêm 29 textos jurídicos individuais e 25 entendimentos, decisões e declarações ministeriais, onde estão especificados compromissos e obrigações adicionais dos seus membros, que devem observar os parâmetros básicos desses acordos ao definirem suas políticas comerciais. Ou seja, fixam as regras que devem ser observadas no jogo do comércio internacional, de modo a garantir condições gerais de competição aos produtores estrangeiros nos mercados externos. Assim, o viés dos acordos da OMC é rule-oriented e não results-oriented.[Hoekman e Kostecki, 1995, p. 24].

Os objetivos mais amplos das novas normas, além da maior previsibilidade das condições em que operam o comércio internacional, são a garantia de acesso aos mercados e a competição justa. Por trás destes dois objetivos estão dois princípios básicos: a não-discriminação e a reciprocidade, que muitas vezes parecem entrar em contradição.

A não-discriminação é o principio fundamental do sistema multilateral de comércio e está expresso nos acordos do GATT/OMC através de duas regras: as cláusulas da nação mais favorecida (artigo I) e de tratamento nacional (artigo III).

Universitas - Relações Int., Brasília, v. 2, n.2, p. 109-125, jul./dez. 2004 
De acordo com a primeira clausula, os membros estão obrigados a conceder aos produtos dos demais membros um tratamento não menos faturável do que aquele que dispensam aos produtos de qualquer outro país. Assim, se for de $3 \%$ a menor tarifa de importação cobrada de um determinado produto por membro, o mesmo tratamento deve ser aplicado imediata e incondicional mente às importações desse bem originárias de todos os membros da OMC.

A cláusula da nação mais favorecida é útil, sobretudo para os países com menor poder de barganha nas negociações internacionais, que automaticamente se beneficiam das reduções tarifárias negociadas bilateralmente por grandes produtores e importadores, ao mesmo tempo em que lhes dá alguma garantia de que não serão alvos preferenciais de medidas protecionistas durante períodos de desaceleração econômica ou de perda de competitividade das indústrias dos países desenvolvidos.

$\mathrm{Na}$ prática, no entanto, os países em desenvolvimento terminaram sendo os mais atingidos pelas políticas protecionistas adotadas pelos desenvolvidos a partir do final da década de 70 .

Há, porém, algumas exceções à cláusula da nação mais favorecida, relacionadas, sobretudo com os acordos de integração econômica e com as preferências tarifárias que podem ser concedidas pelos países desenvolvidos àqueles em desenvolvimento. [Rêgo, 1996, p.13].

A segunda regra estabelece que, após ingressar em um determinado mercado, o produto importado deve receber um tratamento não menos favorável do que aquele dispensado ao similar nacional. Ou seja, não pode estar sujeito a impostos ou quaisquer outras restrições maiores do que aquela imposta aos bens produzidos internamente.

Assim, enquanto a cláusula da nação mais favorecida busca evitar a existência de discriminação entre os diversos países fornecedores de um determinado produto, a cláusula do tratamento nacional procura impedir a discriminação do produto importado em relação aos produtos nacionais.

Universitas - Relações Int., Brasília, v. 2, n.2, p. 109-125, jul./dez. 2004 
No que se refere ao acordo sobre serviços, destaque-se que a concessão de tratamento nacional somente é obrigatória para países que explicitamente assumirem esse compromisso.

Disposições quanto ao tratamento não-discriminatório também estão contidas em outros acordos da OMC, com normas de origem, inspeção prévia à expedição, medidas de investimentos, relacionadas com o comércio (Trims) e a aplicação de medidas sanitárias e fitossanitárias.

O princípio da reciprocidade complementa a cláusula da nação mais favorecida, limitando o incentivo por ela conferido à ocorrência de free-riding. As negociações realizam-se através da troca de concessões em termos de acesso a mercados, e cada negociador procura obter contrapartidas para aquilo que está disposto a oferecer. $\mathrm{Na}$ verdade, é a reciprocidade que torna possível a realização de uma liberalização mais ampla e o estabelecimento de um código de conduta multilateral. O equilíbrio resultante entre direitos e obrigações vai depender do poder de barganha de cada país na negociação. [Rêgo, 1996, p. 14].

\section{Sistema de solução de controvérsias da OMC}

O Mecanismo de solução de controvérsias do GATT, em vigor de 1947 a 1994. Pouco eficaz, devido aos prazos indefinidos, à exigência de adoção de relatórios por consenso e à inexistência de penalidade por descumprimento (mais freqüente nos últimos anos). Baixa complexidade técnica e jurídica: relatórios de pouca profundidade. Cerca de 100 painéis foram concluídos nos 47 anos de vigência do sistema, ou pouco mais de dois por ano, segundo dados de 2003.

O Mecanismo de solução de controvérsias da OMC, em vigor desde 1995. Processo mais estruturado, com prazos definidos, adoção automática de relatórios e possibilidade de retaliação por descumprimento. Possibilidade de recurso ao Órgão de Apelação. Crescente complexidade técnica e jurídica: relatórios de centenas de páginas. Prazos previstos para a disputa: um ano (sem apelação) a 15 meses (com apelação) - casos mais complexos geralmente extrapolam

Universitas - Relações Int., Brasília, v. 2, n.2, p. 109-125, jul./dez. 2004 
esses prazos. Desde 1995, foram compostos mais de 90 painéis, cerca de 10 por ano.

As Dificuldades que persistem ou se agravaram: custo elevado e maior complexidade dificultam a participação de países em desenvolvimento (PVD); eficácia da retaliação depende do país que a aplica; prazos com freqüência descumpridos. O Brasil e o Mecanismo de Solução de Controvérsias da OMC. O Brasil é o PVD que mais participou em contenciosos: cerca de 35 disputas, a maior parte como demandante (nem todas chegaram a painel). De acordo com o Ministério das Relações Exteriores, até dezembro de 2003, o Brasil obteve ganho de causa na grande maioria dos casos; no atual processo de revisão do sistema, o País defende:

ü preservação e ampliação das cláusulas de tratamento especial e diferenciado e opõe-se a qualquer modificação que dificulte o acesso dos PEDs;

ü procedimento acelerado para julgar medidas condenadas em disputa anterior;

ü na fase de implementação das decisões, compensação, que fomenta o comércio, em lugar de retaliação, que o restringe.

\section{Considerações Finais}

A lógica das regras multilaterais de comércio ainda é basicamente determinada pelos Estados-Nacionais, enquanto que a lógica da produção e do comércio mundial está cada vês mais acima das nacionalidades.

Cabe destacar que o sistema multilateral de comércio, no longo prazo, é o mais adequado para reduzir a pobreza e a criação de empregos. Deve-se considerar, também, que o sistema comercial em vigor desde a Rodada Uruguai foi, apesar de suas imperfeições, benéfico para a maior parte dos países.

De acordo com a OMC, já existem 400 acordos firmados ou em negociação no mundo. O maior problema é que grande parte destes

Universitas - Relações Int., Brasília, v. 2, n.2, p. 109-125, jul./dez. 2004 
acordos exclui países pobres e, portanto, são prejudiciais ao comércio internacional.

A opção estratégica pela liberalização comercial aumentou significativamente os graus de liberdade da ação brasileira nos foros multilaterais e permitiu a participação ativa em processo de integração. [Abreu e Frisch, 1996, p.56].

A combinação das mudanças radicais em curso na política comercial brasileira com as transformações no sistema multilateral de comércio impõe a necessidade de reavaliação da política comercial brasileira. Frente à importância destas transformações, não é surpreendente que resultem propostas de significativa reorientação ou redefinição de posturas tradicionais. [Abreu e Frisch, 1996, p.60].

A opção pela OMC representa na verdade uma conseqüência lógica das opções que o Brasil fez no plano multilateral. De fato, com o declínio da UNCTAD, e posteriormente do GATT, a OMC, se tornou o único fórum real para discutir comércio ou nas expressões utilizadas em Genebra o único jogo em andamento.

A posição do Brasil no GATT/OMC evoluiu de uma posição puramente obstrucionista ou defensiva quando dos preparativos para o lançamento da Rodada Uruguai (1982-1986) até 1988, para uma posição francamente construtiva de apoio ao texto final preparado por Dunkel (Draft Final Act), a partir de 1988 quando há uma mudança na política brasileira em relação ao GATT e a futura OMC. [Caldas e Ernst, 2003, p.151]

Esse apoio do Brasil ao Acordo Fina, depois modificado principalmente no tema agrícola não implicou, assim como não implica um apoio geral e irrestrito do Brasil ao conteúdo do texto per se. O apoio do Brasil foi mais ao esforço e ao exercício de se negociar globalmente uma liberalização comercial do que um assentimento ao conteúdo especifico de cada um dos capítulos.

Como notou um diplomata brasileiro em Genebra, a opção do Brasil era entre um mau acordo ou acordo nenhum, aonde prevaleceria a lei do mais forte. Foi nesse contexto, juntamente com a incapacidade da UNCTAD de gerar qualquer resultado prático desde o SGP (Sistema Geral de Preferências) que o Brasil "optou” pelo GATT.

Universitas - Relações Int., Brasília, v. 2, n.2, p. 109-125, jul./dez. 2004 
Isso não significa, portanto, que a $\mathrm{OMC}$ é o órgão preferido pelo Brasil ou que pretenda seguir de forma entusiasmada os resultados da OMC ou de qualquer uma de suas Rodadas. A Rodada Uruguai é exemplo disso. Depois de concordar em limitar as suas tarifas a um pico máximo de $35 \%$, o Brasil já aumentou as mesmas em pelo menos três setores: têxteis, brinquedos e automóveis. Nesse último caso não apenas o Brasil aumentou suas tarifas como criou um verdadeiro regime completamente fora das normas da OMC e está tentando aplica-lo ao MERCOSUL. Dessa forma, o apoio do Brasil à OMC, assim como o apoio do Brasil a liberalização comercial, é na melhor das hipóteses seletivo ou restrito a falta de opções por algo mais atraente.[Machado e Veiga, 1997, p.33-42]

\section{Referência Bibliográfica}

ABREU, Marcelo de Paiva; FRITSCH, Winston. Aspectos estratégicos da política comercial brasileira. In J.A.G. de Albuquerque (org.), Sessenta Anos de Política Externa 1930-1990, volume II, Diplomacia para o Desenvolvimento, Cultura Editores Associados, São Paulo, 1996.

ÁlVARES, J., F. Acordos da Rodada Uruguai: uma visão geral. mimeo, 1994.

AMARAL Júnior, Alberto. A OMC e o comércio internacional. São Paulo: Edições Aduaneiras, 2002.

CALDAS, Ricardo, ERNST, Christoph. ALCA,APEC,NAFTA e União Européia.Rio de Janeiro: Lúmen Júris.2003.

HOEKMAN,B., KOSTECKI, M. The political economy of the world trading system: from Gatt to WTO. Oxford: Oxford University Press, 1995.

KRUGMAN, P., OBSTFELD,M. International economics: theory and policy. New York: Harpers Collins College Publishers, Third Edition, 1994.

MACHADO, João Bosco \& VEIGA, Pedro da Motta. A ALCA e a Estratégia Negociadora Brasileria. In Revista Brasileira de Comércio Exterior, n. 51, Estudos FUNCEX, Abril -Junho. 1997.

Universitas - Relações Int., Brasília, v. 2, n.2, p. 109-125, jul./dez. 2004 
NAKABA, Minoru. OMC e o Regionalismo.São Paulo: Edições Aduaneiras, 2002.

RÊGO. Elba Cristina Lima. Textos para Discussão 51. Rio de Janeiro: BNDES, 1996.

Sistema BNDES. Sinopse Internacional, n. 5. Rio de Janeiro, 1994.

THORSTENSEN, Vera. OMC - Organização Mundial do Comércio: as regras do comércio internacional e a rodada do milênio. São Paulo: Edições Aduaneiras, 1999.

Universitas - Relações Int., Brasília, v. 2, n.2, p. 109-125, jul./dez. 2004 